IZA DP No. 6935

Efficiency in a Search and Matching Economy with a Competitive Informal Sector

Olivier Charlot

Franck Malherbet

Mustafa Ulus

October 2012 


\title{
Efficiency in a Search and Matching Economy with a Competitive Informal Sector
}

\author{
Olivier Charlot \\ Université de Cergy-Pontoise, THEMA and CIRPEE \\ Franck Malherbet \\ Université de Rouen, CREST, Ecole Polytechnique, IZA and fRDB \\ Mustafa Ulus \\ GIAM, Galatasaray University
}

\section{Discussion Paper No. 6935 \\ October 2012}

\author{
IZA \\ P.O. Box 7240 \\ 53072 Bonn \\ Germany \\ Phone: +49-228-3894-0 \\ Fax: +49-228-3894-180 \\ E-mail: iza@iza.org
}

\begin{abstract}
Any opinions expressed here are those of the author(s) and not those of IZA. Research published in this series may include views on policy, but the institute itself takes no institutional policy positions. The IZA research network is committed to the IZA Guiding Principles of Research Integrity.

The Institute for the Study of Labor (IZA) in Bonn is a local and virtual international research center and a place of communication between science, politics and business. IZA is an independent nonprofit organization supported by Deutsche Post Foundation. The center is associated with the University of Bonn and offers a stimulating research environment through its international network, workshops and conferences, data service, project support, research visits and doctoral program. IZA engages in (i) original and internationally competitive research in all fields of labor economics, (ii) development of policy concepts, and (iii) dissemination of research results and concepts to the interested public.
\end{abstract}

IZA Discussion Papers often represent preliminary work and are circulated to encourage discussion. Citation of such a paper should account for its provisional character. A revised version may be available directly from the author. 
IZA Discussion Paper No. 6935

October 2012

\section{ABSTRACT \\ Efficiency in a Search and Matching Economy with a Competitive Informal Sector ${ }^{*}$}

We consider a dual labor market with a frictional formal sector and a competitive informal sector. We show that the size of the informal sector is generally too large compared to the optimal allocation of the workers. It follows that our results give a rationale to informalityreducing policies.

JEL Classification: E24, E26, J60, L16, O1

Keywords: $\quad$ search and matching models, informality, efficiency

Corresponding author:

Franck Malherbet

CREST

Macroeconomic laboratory

15, boulevard Gabriel Péri

92245 Malakoff cedex

France

E-mail: franck.malherbet@ensae.fr

\footnotetext{
* We would like to thank an anonymous referee and $\mathrm{O}$. I'Haridon for helpful suggestions and discussions. Mustafa Ulus gratefully acknowledges support of Galatasaray University through the research funding under grant no: 12.103 .003 supervised by Dr. Burak Gurbuz. The usual disclaimer applies.
} 


\section{Introduction}

Informal or unregistered employment is substantial in many countries, especially in developing ones. It is now well documented that informal and formal labor markets do not share the same characteristics (see e.g. Fields, 2011). In this note, we consider a dual labor market divided between a formal sector subject to matching frictions and a competitive informal sector. ${ }^{1}$ In this framework, workers can take an informal job that can be found instantaneously, or search for a formal job. We show that the workers do not take into account the positive externalities they create on the formal firms' search costs, so that the decentralized outcome features a lower than socially optimum number of workers participating to the formal labor market. Accordingly, there is room for corrective policies to reduce participation to the informal sector.

\section{The model}

The model builds on the conventional continuous-time search and matching framework $\grave{a}$ la Pissarides (2000), and is extended to incorporate a competitive informal sector, as in Zenou (2008). We consider an economy populated with a continuum of infinitely-lived, risk neutral and homogenous workers and a continuum of identical firms holding at most one vacancy. All agents discount future payoffs at the rate $r>0$. Among workers $M$ and $L$ work informally and formally respectively, while there are $U$ unemployed workers searching for a (formal) job. The size of the population is then defined as:

$$
N=M+L+U
$$

Production results either from formal or informal activities. There is an endogenously sized continuum of registered firms, each endowed with a single job slot, which can be either filled and producing, or vacant and searching for a worker. Registered firms produce with a fixed coefficient technology, yielding $y$ units of output per worker. Total output realized by unregistered firms results from an aggregate production function $F(M)$ with $F^{\prime}>0, F^{\prime \prime}<0$.

The formal sector has matching frictions captured by a customary matching function with standard properties. The flow of hires $\mathcal{M}$ writes $\mathcal{M} \equiv \mathcal{M}(\mathcal{V}, U)$, where $\mathcal{V}$ denotes the number of vacancies. Let $\theta \equiv \mathcal{V} / U$ be the labor market tightness. On average, a vacancy meets a worker at rate $q(\theta) \equiv$ $\mathcal{M}(\mathcal{V}, U) / \mathcal{V}=\mathcal{M}(1,1 / \theta)$, with $\frac{\partial q(\theta)}{\partial \theta}<0$, whereas an unemployed finds a job at rate $\mathcal{M}(\mathcal{V}, U) / U=$ $\mathcal{M}(\theta, 1)=\theta q(\theta)$, with $\frac{\theta \partial q(\theta)}{\partial \theta}>0$. We assume that frictions are negligible in the informal sector so that workers and firms match instantaneously.

\footnotetext{
${ }^{1}$ For a discussion of why the informal sector should have less frictions see e.g. Zenou (2008).
} 
The flow into unemployment results from match-specific shocks occuring at Poisson rate $\delta$. The motion law for $U$ satisfies:

$$
\dot{U}=\underbrace{(N-M)(1-u) \delta}_{\text {number of separations }}-\underbrace{(N-M) u \theta q(\theta)}_{\text {number of hires }}
$$

where $N-M$ and $u=U /(N-M)$ indicate the size of the formal sector and the unemployment rate respectively. The steady-state sectoral unemployment rate writes:

$$
u=\frac{\delta}{\delta+\theta q(\theta)} .
$$

\section{The decentralized economy}

Workers' expected utility of being unemployed and searching for a job or employed in a registered firm can be defined as follows:

$$
\begin{aligned}
r S & =\theta q(\theta)(W-S) \\
r W & =w+\delta(S-W)
\end{aligned}
$$

Job seekers get a payoff that is normalized to zero. At rate $\theta q(\theta)$ unemployed workers will be employed leading to a capital gain of $(W-S)$. A formal worker gets the net wage $w$ in each period and will become unemployed at Poisson rate $\delta$ in which case, the workers incur a capital loss given by $(S-W)$. The informal sector is competitive, so that informal workers are paid their marginal product. As a result, the discounted value of being informal writes:

$$
r I=\omega=F^{\prime}(M)
$$

The value to the firm of holding a vacancy or a filled job are defined as follows:

$$
\begin{aligned}
r V & =-\gamma+q(\theta)(J-V) \\
r J & =y-w+\delta(V-J)
\end{aligned}
$$

where $\gamma$ is the cost of holding a vacancy. At rate $q(\theta)$, the firm meets a worker, which yields a capital gain $(J-V)$. A filled job yields instantaneous profits $y-w$, where $w$ is the wage paid to the worker. With exogenous probability $\delta$, the match will be destroyed and the firm incurs a capital loss $(V-J)$.

Workers allocate themselves between the two types of jobs so that in steady state, they must be indifferent between searching for a formal job and being employed by an unregistered firm. We get:

$$
r S=r I
$$


Formal Wages. Matching Frictions imply that upon matching, a firm-worker pair generates a local monopoly rent. This rent is shared through a generalized Nash criterion which determines formal wages according to $\max (W-S)^{\beta}(J-V)^{1-\beta}$, where $\beta$ denotes the workers' bargaining power. Using (4), (5), (7), (8), the free entry condition, $V=0$, and the FOCs of the bargaining problem, we get the standard wage equation:

$$
w=\beta(y+\gamma \theta)
$$

Labor Demand. Using the fact that $V=0$, together with (7) and (8), we get:

$$
\frac{\gamma}{q(\theta)}=\frac{y-w}{r+\delta}
$$

Free entry implies that firms enter the labor market until the expected cost of holding a vacancy $\frac{\gamma}{q(\theta)}$ equals expected profits $\frac{y-w}{r+\delta}$. Equation (11) is analogous to a labor demand equation. Using (10), the free entry condition rewrites as:

$$
\frac{\gamma}{q(\theta)}=y \frac{1-\beta}{r+\delta+\beta \theta q(\theta)}
$$

Informal Jobs. Using (4), (7) and the focs of the bargaining problem, the value of being unemployed rewrites as $r S=\frac{\beta}{1-\beta} \theta \gamma$. Combining with the arbitrage condition (9) and the asset equation (6), we get:

$$
F^{\prime}(M)=\frac{\beta}{1-\beta} \gamma \theta
$$

and finally the steady-state number of informal workers:

$$
M=F^{\prime-1}\left(\frac{\beta}{1-\beta} \theta \gamma\right) .
$$

\section{The optimum}

We compare the market outcome to the commands of a benevolent central planner, aimed at maximizing the following social welfare function (see e.g. Pissarides 2000):

$$
\Omega=\int_{0}^{\infty} e^{-r t}[y L-\gamma \mathcal{V}+F(M)] \mathrm{d} t
$$

The first term within brackets, $y L$, is the total output of the formal sector. The second term, $\gamma \mathcal{V}$, corresponds to the total costs of posting vacancies in the formal sector. Finally, the third term, $F(M)$, is the total output of the informal sector. While optimizing social welfare, the planner is then subject to the same feasibility constraints (1), to the same definition of tightness $\theta \equiv \mathcal{V} / u(N-M)$, and to 
the same constraints on the evolution of unemployment as in the market outcome (2). The planner controls the number of informal workers $M$, tightness $\theta$, and the unemployment rate $u$.

Optimality conditions imply that the size of the informal activities, $M^{c}$ and sectoral tightness, $\theta^{c}$, result from:

$$
\begin{gathered}
F^{\prime}\left(M^{c}\right)=y\left(1-u^{c}\right)-\gamma \theta^{c} u^{c} \\
\frac{\gamma}{q\left(\theta^{c}\right)}=y \frac{1-\eta^{c}}{r+\delta+\eta^{c} \theta^{c} q\left(\theta^{c}\right)}
\end{gathered}
$$

where $\eta^{c}=-\theta^{c} q^{\prime}\left(\theta^{c}\right) / q\left(\theta^{c}\right)$.

When allocating workers between formal and informal activities, the planner equalizes the marginal product of informal work, $F^{\prime}\left(M^{c}\right)$ to the marginal product of formal activities net of search costs, $y\left(1-u^{c}\right)-\gamma \theta^{c} u^{c}$. The planner determines tightness $\theta^{c}$ by equalizing expected search $\operatorname{costs} \gamma / q\left(\theta^{c}\right)$ to the social return to job creation $y \frac{1-\eta^{c}}{r+\delta+\eta^{c} \theta^{c} q\left(\theta^{c}\right)}$. Equation (17), is thus identical to the free entry condition (12) in equilibrium when the Hosios condition (Hosios, 1990) holds, i.e., when $\beta=\eta$. Having determined tightness in the centralized outcome, the divide between formal and informal activities results from (16). Using (17) and after substitution of $u^{c}=\frac{\delta}{\delta+\theta^{c} q\left(\theta^{c}\right)}$, we get:

$$
F^{\prime}\left(M^{c}\right)=\frac{\eta^{c}}{1-\eta^{c}} \gamma \theta^{c}+r \frac{\gamma \theta^{c}}{\left(1-\eta^{c}\right)\left(\delta+\theta^{c} q\left(\theta^{c}\right)\right)}
$$

to be compared to (13) in equilibrium.

In the general case, there is a misallocation of workers between formal and informal activities. From the comparison between (13) and (18), it turns out that the return to participation to formal activities is larger for the central planner than for the workers. Even when $\beta=\eta$ the private return to search for a formal occupation $\frac{\beta}{1-\beta} \gamma \theta^{*}$ will be lower than the social return $\frac{\eta}{1-\eta} \gamma \theta^{c}+r \frac{\gamma \theta^{c}}{(1-\eta)\left(\delta+\theta^{c} q\left(\theta^{c}\right)\right)}$, so that too many workers will choose to go informal in the decentralized outcome $\left(M^{c}<M^{*}\right)$.

Proposition 1. Centralized vs decentralized outcome when $r>0$. In equilibrium when $r>0$, centralized and decentralized outcomes do not coincide whenever the Hosios condition, $\beta=\eta$, holds. We have that $\theta^{c}=\theta^{*}$ and $M^{c}<M^{*}$.

Proof. Straightforward from the comparison of eq. (12), (13), (17) and (18).

It follows that there are too few formal jobs and too many informal jobs in equilibrium when the discount rate is strictly positive. Therefore there is a rationale for economic policies that foster formal employment. An intuition for this result is the following. The basic cause of the inefficiency in this model is analogous to a hold-up problem: Ex-ante, a worker decides which sector to enter. If he enters the formal sector, he only recoups a fraction $\beta$ of the search cost required to find a formal sector job. 
Similar to the standard hold-up problem, $\beta$ cannot be set in a way that gets both the vacancy creation decision and the ex-ante investment decision (which sector to enter) right ${ }^{2}$.

Let us now turn to case where the discount rate, $r$, goes to zero. The next proposition summarizes our results.

Proposition 2. Centralized vs decentralized outcome when $r \rightarrow 0$. In equilibrium when $r \rightarrow 0$, centralized and decentralized outcomes coincide whenever the Hosios condition, $\beta=\eta$, holds. We have that $\theta^{c}=\theta^{*}$ and $M^{c}=M^{*}$.

Proof. Idem.

Hence, if the Hosios condition holds, the equilibrium is constrained efficient when $r \rightarrow 0$. However, even in this case, there is no particular reason to believe that the condition $\beta=\eta$ holds. It is possible to investigate the impact of a shift in the bargaining power away from the Hosios condition when $r \rightarrow 0$. In this case, tightness does not generally reach its optimal value. As a result, this will translate into a sub-optimally low return to participation to formal activities, as $\frac{\beta}{1-\beta} \gamma \theta^{*}$ is maximized when the Hosios condition holds. It follows that an inefficiently high number of workers choose to go informal, i.e. $M^{*}>M^{c}$. This occurs because workers choose between formal and informal activities by comparing the expected return from each activity, and do not internalize the beneficial impact of their participation to the formal sector on firms' expected search costs. This is is summarized by the following proposition:

Proposition 3. Centralized vs decentralized outcome when $r \rightarrow 0$ and $\beta \neq \eta$. In equilibrium when $r \rightarrow 0$ and $\beta \neq \eta$, we have $M^{c}<M^{*}$.

Proof. Idem.

\section{Conclusion}

In this note, we have studied a search and matching model with a frictional formal sector and a competitive informal sector. We have shown that a laissez-faire economy is inefficient even if the Hosios condition holds. In this respect, our results are complementary to the findings of e.g. Acemoglu (2001) or Albrecht et al. (2010). We claim that informality induces a suboptimal participation to the formal sector. This provides a rationale for corrective policies fostering formal employment.

\footnotetext{
${ }^{2}$ We would like to thank an anonymous referee for suggesting this interpretation.
} 


\section{References}

[1] Acemoglu, D., 2001, "Good jobs versus bad jobs", Journal of Labor Economics, 19, 1-21.

[2] Albrecht, J., Navarro, L. and Vroman, S., 2010, "Efficiency in a search and matching model with endogenous participation", Economics Letters, 106, 48-50.

[3] Fields, G.S., 2011, "Labor market analysis for developing countries", Labour Economics, 18, S16-S22.

[4] Hosios, A.J., 1990, "On the efficiency of matching and related models of search and unemployment", The Review of Economic Studies, 57, 279-298.

[5] Pissarides C., 2000, Equilibrium Unemployment Theory, Second Edition (Cambridge: MIT Press).

[6] Zenou, Y., 2008, "Job search and mobility in developing countries. Theory and policy implications", Journal of Development Economics, 86, 336-355. 